Europe's Journal of Psychology, 7(3), pp. 408-418

www.ejop.org

\title{
On culture and human development: Interview with Barbara Rogoff
}

\section{By Vlad Glăveanu EJOP Editor}

In this interview Professor Barbara Rogoff explores the many ways in which culture shapes the course of human development, and illustrates this with several findings from her past as well as most recent work. These reveal the vital importance of growing up in a family and a community for the human child and participating, from early on, in their various rituals and practices. Building on and enriching cultural psychological sources, Professor Rogoff offers us a comprehensive framework with which to understand both cultural and developmental phenomena and, above all, their multiple intersections. Her suggestions will prove to be invaluable for all the students of culture and community life in their ontogenetic expression.

Barbara Rogoff is UC Santa Cruz Foundation Distinguished Professor of Psychology, Fellow of the American Psychological Society, the American Anthropological Association, the American Psychological Association, and the American Educational Research Association. She served as Editor of Human Development, Study Section member for the National Institute of Child Health and Human Development, and committee member on the Science of Learning for the National Academy of Science. Her book Apprenticeship in Thinking (1990) received the Scribner Award from the American Educational Research Association, Learning Together: Children and Adults in a School Community (2004) was finalist for the Maccoby Award of the American Psychologist Association, and The Cultural Nature of Human Development (2003) won the William James Book Award of the American Psychological Association. Her latest book, Developing Destinies (2011), is based on her more than 3 decades of research in a Mayan town in Guatemala.

Address for correspondence: Barbara Rogoff, Psychology Department, UCSC, Santa Cruz, CA, 95064

Email: brogoff@ucsc.edu 
EJOP: Professor Rogoff, your work over the past decades has dealt extensively with the intersections between culture and development, at a time when more mainstream approaches were focused on intra-psychological aspects. What made you interested in studying the cultural aspects of growing up in different human communities?

Prof. Rogoff: While I was a grad student studying cognitive development, I had the opportunity to work and live in a Mayan community in Guatemala, thanks to Professors Jerome Kagan, Beatrice Whiting, Shep White, and Ben and Lois Paul. I was interested in how Mayan children learned many complex skills, such as weaving intricate fabrics.

I was puzzled when I asked mothers how they taught their daughters to weave and they responded that they did not teach the girls; the girls simply learned. This went against my assumptions (perhaps derived from having spent 19 years in school) that children learn by being taught. So I asked more questions and watched, and over the intervening three decades, I learned that the children learn through observing keenly and contributing to ongoing endeavors, with the support of their families.

So, the children are not "taught" lessons like in many schools, with exercises and lengthy explanations out of the context of productive involvement. At the same time, they do not simply "discover" how to weave and to carry out other complex activities. Rather, they attentively engage in the activities of their community, together with the people around them, who provide access to observe, show children how to contribute, support children's efforts, and provide pointers for improvement. This is a mutually constituting process, in which individual, interpersonal, and cultural/community aspects are all crucial.

EJOP: Today there is growing interest in culture and how it impacts human life, both in psychology and related disciplines. What would you say we learned and what we still need to learn about "development in (cultural) context"?

Prof. Rogoff: What we have learned about "development in cultural context" is the theme of my book The Cultural Nature of Human Development (Oxford University Press, 2003). In brief, we know that culture matters, and we have some ideas of how culture matters. For example, one way that culture matters is that cultural communities provide opportunities and constraints in what settings children frequent - in some communities, children are included in most events and activities; in some other communities, children spend most of their day segregated from the broader community in settings designed to keep them separate (such as many daycare 
settings and schools). My book develops the themes of how culture matters within the classic areas of human development such as cognitive development and social relations among children and their families and peers.

What do we still need to learn? We need to develop clearer ideas of cultural patterns in human development. Understanding patterns of cultural variations and similarities would allow us to understand some generalities, and not just say 'every place is different.' At the same time, we need more nuanced ways to understand the patterns, and not just lump whole continents together or split the world into East/West or other dichotomies.

In The Cultural Nature of Human Development, I argued for looking at culture in terms of cultural practices that show both stabilities and changes across generations. I proposed several patterns that I think are central to understanding the cultural basis of human development. One involves the integration of children in community life (in contrast to segregating them in a 'child world'). Children who are part of community life have many opportunities to learn by observing and contributing in real ways, through Intent Community Participation (in contrast to depending on adults to devise artificial exercises for their learning). I believe that this contrast outlines two very different patterns organizing children's lives and learning. The book explores the implications of these patterns - and others - for children's learning, thinking, communic ation, social interactions, developmental transitions, and roles.

EJOP: From a more methodological perspective, it has often been acknowledged that studying culture and also development is a very difficult endeavor due to their intrinsic complexity. Trying to look at them both and their interconnectedness surely faces the researcher with an extremely rich and diverse set of data. How is it that such data can be obtained and, most importantly, made sense of?

Prof. Rogoff: The study of culture and development go together: Culture is best understood historically, examining how current practices reflect past circumstances and ideas, and seeing how new generations adapt practices of those who went before. This historical approach involves the development of individuals as well as of generations. Development is best understood culturally; all people develop in the context of particular times and places. These ideas are developed in The Cultural Nature of Human Development and also in my new book, Developing Destinies: A Mayan Midwife and Town (Oxford, 2011).

With regard to more specific methodological approaches, it is helpful to make use of the tools available in both qualitative and quantitative approaches (Rogoff, Mistry, 
Göncü, \& Mosier, 1993; Rogoff, Topping, Baker-Sennett, \& Lacasa, 2002). So me of the studies in my research group have focused ethnographically on a few cases in great depth. In other studies we have made use of ethnographic information to find or devise situations that can be repeated, to be able to look at multiple cases and make comparisons. For example, we have studied the route planning of girl scouts delivering cookies they have sold. And we have devised scenarios based on observations of everyday life, to be able to study children's attention (such as a visit with a toy salesperson and origami and other craft demonstrations).

In our research, we pilot our procedures extensively to make sure that the situation is understood by participants in the way that we intend. We devise our coding schemes to capture the phenomenon about which we want to make conclusions, carefully piloting the coding schemes as well. Before we run statistical analyses, we graph the patterns of the data extensively, often case by case (see casegraphs in Rogoff et al., 1993; Correa-Chávez, Rogoff, \& Mejía-Arauz, 2005). Statistical analyses follow, to help us simplify the data and to check the strength of the patterns we have come to understand through graphing. We try to employ the simplest statistical analyses possible, to communicate findings clearly and to avoid losing the phenomenon in complexities of statistic al analyses.

EJOP: In your work you made use of different theories and models of development, particularly drawing inspiration from the work of Lev Vygotsky. What are the advantages of 'wearing' these particular theoretical lenses?

Prof. Rogoff: I became particularly aware of the work of Vygotsky and his colleagues when I was trying to make sense of my dissertation data, focusing on memory development in Mayan children. Like Scribner, Cole, and others, I was struck with how little the work current in the 1970s helped to understand how people could remember beautifully outside the testing room but have difficulty when given lists of words to say back to a researcher. Vygotsky's theory specified the centrality of social interaction and cultural tools in cognitive development and it opened a new window on processes of learning and development that was sorely needed. I also found the work of Dewey and Gibson to be very helpful as I delved further into understanding how thinking and learning are part of social and cultural processes.

EJOP: Echoes of such sources of inspiration are found in your very useful model of Learning through Intent Community Participation (ICP). Can you please describe briefly your conception and also comment on the model's applicability (perhaps to other contexts in which children's participation in community activities may not be so obvious)? 
Prof. Rogoff: My colleagues and I have been investigating how children learn by observing and pitching in to ongoing activities of their families and communities, especially in communities where children are included as participants in most of community life. We call this cultural tradition learning through Intent Community Participation (Rogoff, Paradise, Mejía-Arauz, Correa-Chávez, \& Angelillo, 2003; Rogoff, Moore, Najafi, Dexter, Correa-Chávez, \& Solís, 2007).

Although children learn by observing and pitching in throughout the world, this approach appears to be especially prevalent in Indigenous communities of the Americas and among people with historical roots in such communities, such as many immigrants to the United States from Mexico and Central America.

Learning through Intent Community Participation seems to be less prevalent in communities where children spend extensive time in Western schooling, but it is nonetheless present in important places: In everyone's first-language learning, we listen closely and pitch in when we have something to communicate. It occurs often in doctoral education and in many preschools. It has been found in some elementary schools, such as the innovative school that was the basis of a book on how adults and children can form collaborative communities of learning (Learning Together: Children and Adults in a School Community, by Rogoff, Goodman Turkanis, \& Bartlett, Oxford, 2001).

One of the reasons that my research group and I are investigating this approach is that we are convinced that it is one of several promising ways that learning situations can be improved, in schools as well as other settings such as museums and family.

We define learning through Intent Community Participation in a prism with 7 interrelated facets (see below).

As summarized in Rogoff (2011, submitted), the 7 facets of learning through Intent Community Participation are as follows:

1. Learners are incorporated in the range of ongoing endeavors of their families and communities, with expectations and opportunities to contribute.

2. Le arners are eager to contribute, belong, and fulfill roles that are valued in their families and communities. Other people present are involved in accomplishing the activity at hand, and may provide guidance. 
3. Learning involves keen attention, during or in anticipation of contributing, guided by community expectations of responsible contribution and sometimes by other people.

4. Social organization involves collaborative engagement in family and community endeavors, with flexible leadership and trust in learners to take initiative, along with others who also participate at a calm mutual pace.

5. Communication occurs through coordination of shared endeavors through articulate nonverbal conversation and parsimonious verbal means, as well as through narratives and dramatization that contextualize information and ideas.

6. The goal of education is transformation of participation, which inv olv es learning to collaborate, with appropriate demeanor and responsibility, as well as learning information and skills, to be responsible contributors belonging in the community.

7. Assessment includes evaluation of the success of the arrangements as well as the learner's progress, in support of learners' contributions, during the endeavor. Feedback is direct, from the outcome of learners' efforts and the acceptance (or not) of the efforts by others as productive contributions. (Rogoff, 2011 submitted)

\section{LEARNing through INTENT COMMUNity PARTICIPATION}

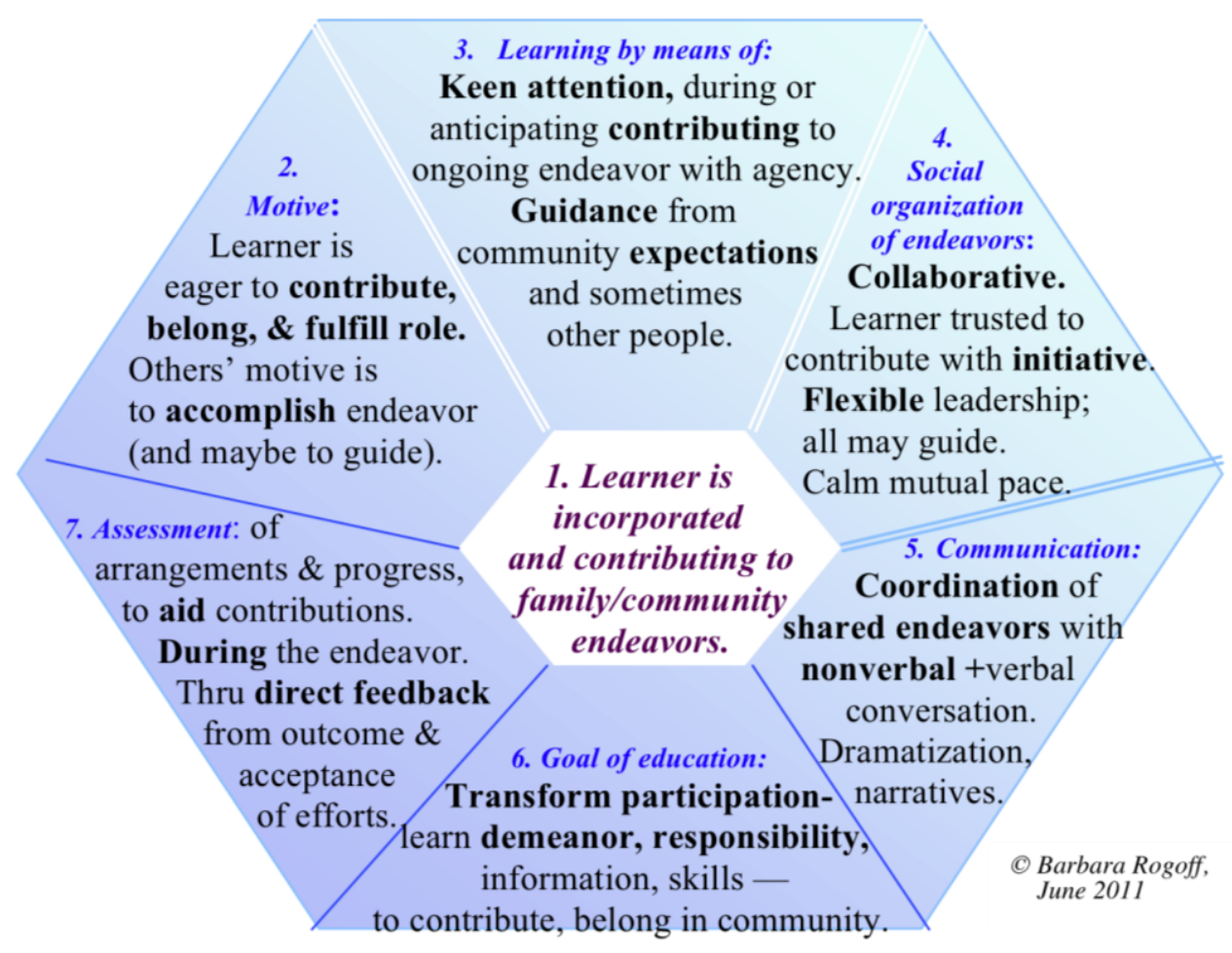

We have developed an international research consortium that focuses on learning through Intent Community Participation; we have met for 8 years. We are developing a website that describes the work of the consortium: http://www.intentcommunityparticipation.net 
EJOP: At an empirical level, you have been interested for a long time in populations with Indigenous heritage (in Mexico, Guatemala, etc.). Your most recent book 'Developing Destinies: A Mayan Midwife and Town' (Oxford University Press, 2011) reflects very well this interest. What is particular about this research context and how are 'destinies developed' within these communities?

Prof. Rogoff: I have worked for 37 years in the Mayan town of San Pedro, in Guatemala, studying child development. That work has been a major source of inspiration for my ideas about how children learn, and especially learning through intent community participation.

In the process, I came to know a leading expert on childrearing, the renowned spiritual midwife Chona Pérez. Over the 37 years that I have known her, I became interested in how she became so expert in birth practices, childrearing, and in the spiritual side of she pherding new souls into the world. Chona's expertise comes from being born with the destiny of being a spiritual midwife (indicated by being born with a small piece of the amniotic sac over her head, as shown in my painting below).

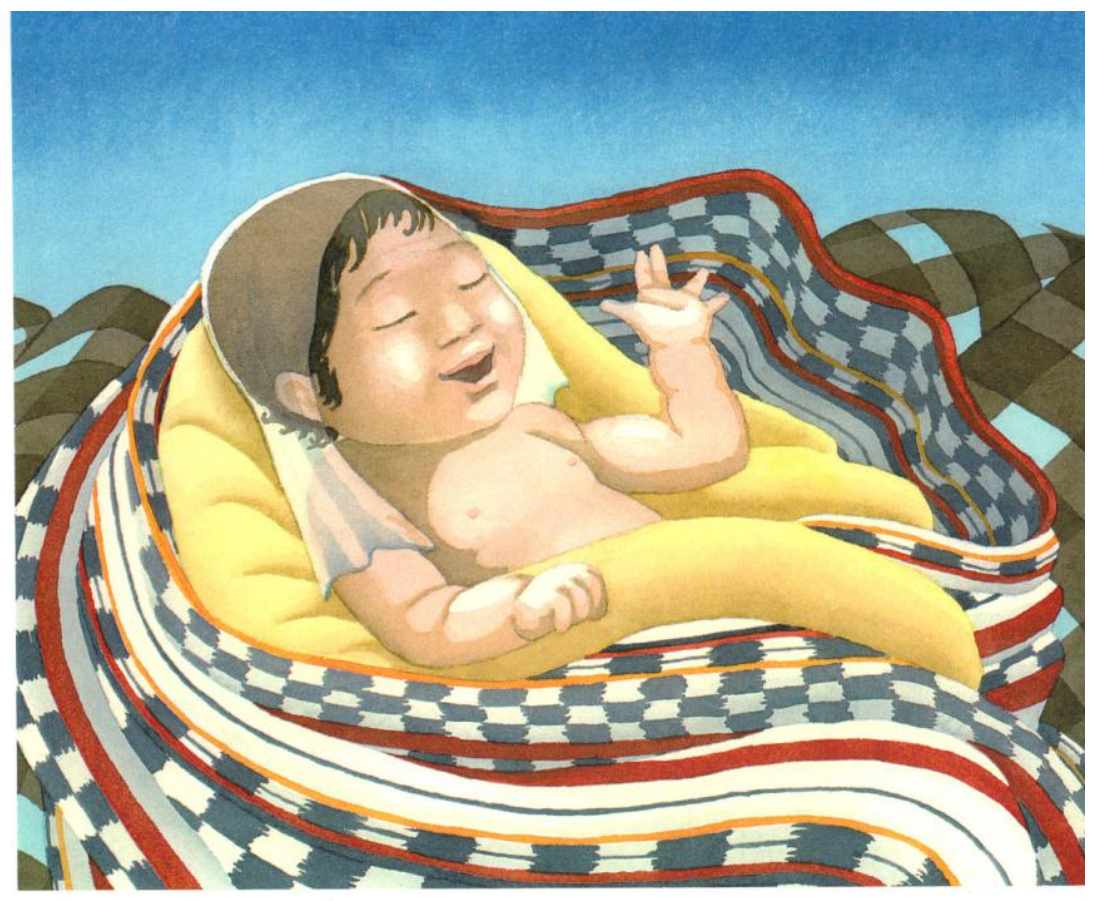

copyright Barbara Rogoff, 2011

The book Developing Destinies: A Mayan Midwife and Town developed into a case study of Chona and of San Pedro, examining changes and continuities in the life and learning of this individual and of her community. The book illustrates theoretical ideas regarding the relation between individual and cultural processes, taking a 
historical view of both. It also examines changes and continuities in ways of organizing children's learning, birth practices, family organization, and other aspects of childrearing in San Pedro.

In the process, the book argues that each of us is born with a sort of destiny, by being born in a particular time and place with specific cultural patterns - and that this destiny develops. As with Chona, we are not limited to what our time and place equip us with; we contribute with our experiences, decisions, and adaptations of what is present at our births. As individuals, we contribute to our cultural communities at the same time that our cultural communities contribute to our development.

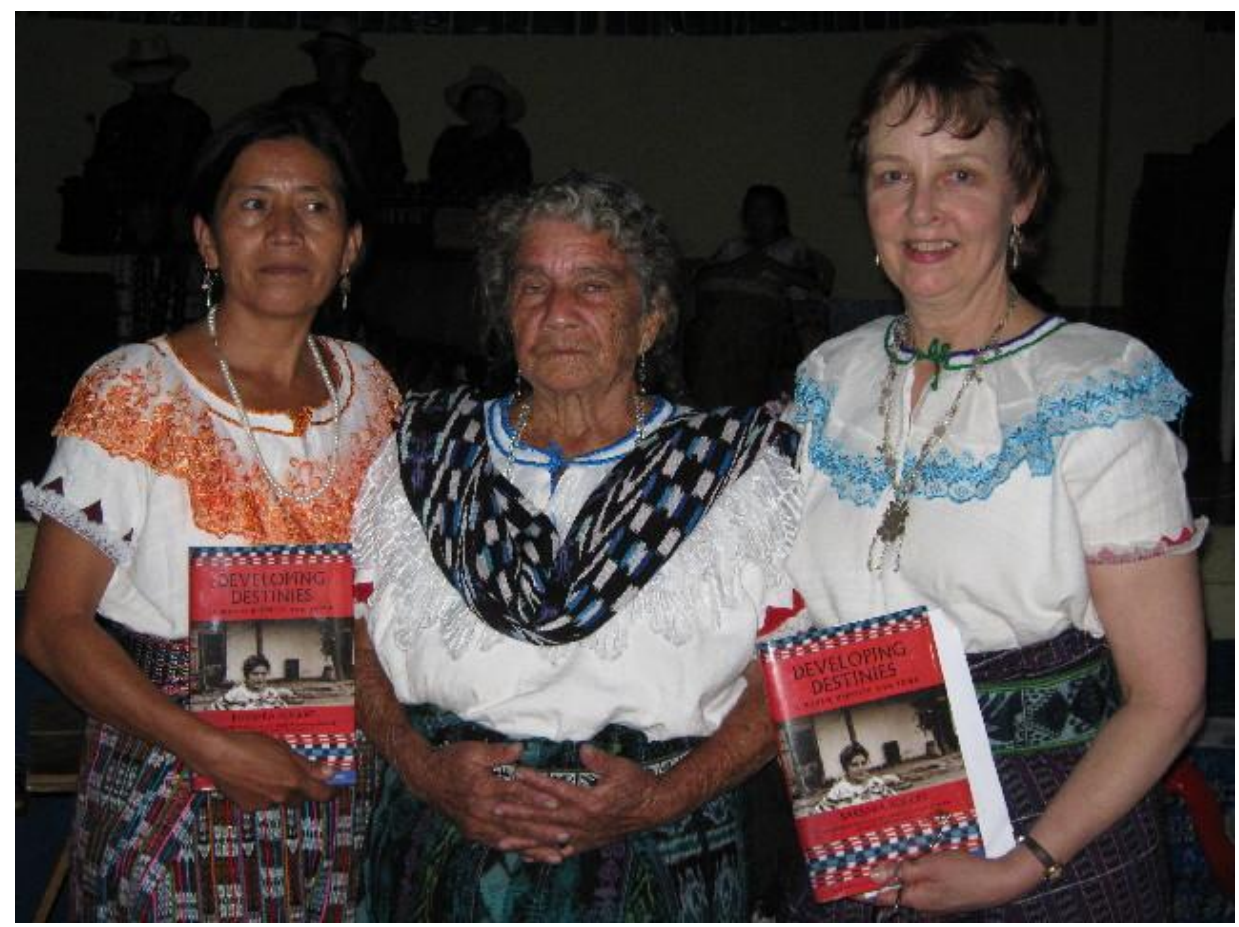

copyright Valerie Magarian 2011

This photo was taken recently at the formal presentation of Developing Destinies to the Mayan town and to the spiritual midwife that are central to the book. I am on the right, Chona Pérez, the midwife, is in the middle, and on the left is my longtime colleague and research assistant, Marta Navichoc Cotuc. We plan for the book to be translated into Spanish and into the Mayan language. My royalties for the book are contributed to the Learning Center and other projects in San Pedro:

http://www.taapit.org/en/about-us/3 1-resumen-general.html More photos and paintings appear on Facebook page "Barbara Rogoff Publications": http://www.facebook.com/barbararogoffpublications

EJOP: At a more practical level, how can we put in practice everything we have learned about the role of communication and participation? How should we design 
programs that help enhance human growth and development, in different cultural contexts?

Prof. Rogoff: A key feature of putting ideas into practice is to adapt them to local circumstances. Programs cannot be 'one size fits all.' A related feature of designing programs is to include the people for whom the programs are designed, as contributors in the planning as well as implementation of the programs. These are widely accepted precepts. My colleagues and I explored them in Learning Together: Children and Adults in a School Community (Oxford, 2001). This book was written collaboratively by teachers, parents, students, and a few researchers involved in an innovative public elementary school, to examine principles of learning collaboratively.

Another important precept is that people can and should learn to do things more than one way. Programs should usually not substitute one cultural pattern for another. Instead, programs can assist people in learning new ways of doing things while maintaining other ways, and can help people learn when to use each approach. This is a matter of enlarging people's repertoires of cultural practices (Gutiérrez \& Rogoff, 2003; Rogoff, 2003). For example, people can flexibly use the approach of learning through Intent Community Participation as well as approaches common in Western schooling, depending on the circumstances.

EJOP: Tow ards the end I would like to ask you about your current research and future projects. How continuous (or not) are they with your previous work.

Prof. Rogoff: I continue to work on understanding learning through Intent Community Participation. My colleagues and I have recently submitted a research monograph that examines how this approach works and how general it is across populations that no longer live in Indigenous communities - people who have migrated or who live in a community that no longer identifies in this way. We are trying to understand the process of survival, adaptation, and resistance of cultural practices stemming from Indigenous communities of the Americas, especially learning through Intent Community Participation. Our work includes immigrants to the US and migrants to Mexican cities from regions of Mexico that have historically involved Indigenous communities, as well as Indigenous communities native to the US, Guatemala, and Mexico.

We study children's integration in the work and other endeavors of their families and communities, their initiative and consideration for the direction of collaborative endeavors, keen attention to surrounding events, helping without being asked, 
coordination with others using articulate nonverbal means, and blending agendas rather than dividing resources.

We also examine the corresponding ways that adults and communities organize learning through Intent Community Participation: expecting children to be present and contributing to the wide range of family and community activities, collaborating with children in a way that provides guidance and leadership and at the same time has room for children's initiative and leadership, blending agendas with a calm measured pace rather than dividing resources or tasks or controlling children, according children responsibility to make sense of the world, and using example, subtle nonverbal conversation, and narrative to shape children's understanding and participation in family and community ways.

EJOP: Finally please address some words to our readers, most of them graduate students and young academics and professionals. What should early students of culture and development be aw are of, focus on and hope for?

Prof. Rogoff: Be aware that there are usually several good ways to do things, not just One Best Way, and that people can learn to do things more than one way. Focus on learning from the situations to which you have access - be alert and open-minded.

Hope for? World peace. Seriously, though.... Understanding each other will hopefully aid the process of achieving a more peaceful and just world.

EJOP: Thank you very much for sharing your thoughts with us.

Barbara Rogoff would like to thank Maricela Correa-Chávez, Katie Silva, Angélica López, Omar Ruvalcaba, Lucía Alcalá, and Andrew Coppens for comments on a prior version of this interview.

\section{References}

Correa-Chávez, M., Rogoff, B., \& Mejía-Arauz, R. (2005). Cultural patterns in attending to two events at once. Child Development, 76, 664-678.

Gutierrez, K., \& Rogoff, B. (2003). Cultural ways of learning: Individual traits or repertoires of practice. Educational Rese archer, 32, 19-25.

Rogoff, B. (2003). The cultural nature of human development. NY: Oxford University Press. 
Translated into Italian (2004). La natura culturale dello sviluppo. Raffaello Cortina Editore.

In Portuguese (2005). A natureza cultural do desenvolvimento humano. Porto Alegre, Brasil: Artmed Editora.

In Japanese (2005), Shin-yo-sha Press. www .shin-yo-

sha.co.jp/mokuroku/books/4-7885-1013-8.htm

Translated into Chinese (2008) Psychological Publishing Co., Ltd. ISBN 978-986191-177-9.

Being translated into Arabic.

Rogoff, B. (2011). Developing destinies: A Mayan midwife and town. NY: Oxford Univ ersity Press.

Rogoff, B., Goodman Turkanis, C., \& Bartlett, L. (2001). Learning together: Children and adults in a school community. New York: Oxford University Press.

Rogoff, B., Mistry, J.J., Göncü, A., \& Mosier, C. (1993). Guided participation in cultural activity by toddlers and caregivers. Monographs of the Society for Research in Child Development, 58 (7, Serial No. 236).

Rogoff, B., Moore, L., Najafi, B., Dexter, A., Correa-Chávez, M., \& Solís, J. (2007). Children's development of cultural repertoires through participation in everyday routines and practices. In J. E. Grusec \& P. D. Hastings (Eds.), Handbook of socialization. (pp. 490-515). NY: Guilford.

Reprinted in French, in G. Brougère \& M. Vandenbroeck (Eds.), Repenser l'éducation des jeunes enfants [Rethinking the education of young children]. (pp. 103-138). Brussels: Peter Lang.

Rogoff, B., Paradise, R., Mejía Arauz, R., Correa-Chávez, M., \& Angelillo, C. (2003). Firsthand learning through intent participation. Annual Review of Psychology, 54, 175-203.

http://arjournals. annualreviews.org/doi/full/10.1 146/annurev .psych.54.101601. 145118 ? cookieset=1

Reprinted [in Spanish] in L. de León (Ed.), Socialización, lenguajes y culturas infantiles: Estudios interdisciplinarios. (pp. 95-134). Mexico City: CIESAS.

Rogoff, B., Topping, K., Baker-Sennett, J., \& Lacasa, P. (2002). Mutual contributions of individuals, partners, and institutions: Planning to remember in Girl Scout cookie sales. Social Development, 11, 266-289. 